\title{
Predicting listening accuracy in the interview with training scores
}

\author{
ALLEN J. SCHUH \\ California State University, Hayward, California 94542
}

\begin{abstract}
The relationship among three sets of test scores was studied: listening accuracy on a test based on a 12-min audio-video tape of an employment interview, and separate accuracy test scores from the lecture and text portions of three examinations in a course in personnel evaluation. Participants were afternoon $(\mathrm{N}=32)$ and evening $(\mathrm{N}=22)$ students taking the course as a graduation requirement. The means and standard deviations for the two sections were not found to be significantly different and were pooled. The intercorrelations between the tests of accuracy were significant $(p<.01)$, and indeed, were not significantly different from each other. A single processing mechanism links perceptual and acoustic systems and acts on the recall and recognition of verbal material whether read or heard. The implications for screening candidates for assignment to interviewing duties are discussed.
\end{abstract}

The purpose of this study was to fill a gap in the research literature on employment interviewing. To date, there have been no studies on the extent of individual differences in listening accuracy of people who are or might be given interviewing assignments. It might be possible to check listening accuracy in one well controlled setting and see whether that performance would have been predictable from other tests on verbal material. Specifically, the purpose of this research was to examine the correlation between a listening accuracy test score from an interview setting and separate test scores from text and lecture material in a course on personnel evaluation. The related research literature (Aiken, Thomas, \& Shennum, 1975; Jenkins, 1974; Mason, 1977; Singer, 1975; Wickelgren, 1973) strongly suggests that the scores should be significantly related.

\section{METHOD}

\section{Participants}

Participants were students enrolled in afternoon $(\mathrm{N}=32)$ and evening $(\mathrm{N}=22)$ sections of a course in personnel evaluation. The course is required of undergraduates in the personnel/industrial relations major and consists of lectures, discussions, and work samples.

\section{Apparatus \\ The apparatus consisted of a Sony tape deck with a 21-in Setchel-Carlson monitor. The audio-video tape used in this study was a 12-min broadcast-quality employment interview of a 26-year-old male dressed casually and seated across from an off-camera interviewer.}

\section{Procedure}

There were three examinations during the quarter that followed the general outline of the required text (Cronbach, 1970). It was possible to identify test items as being from the text or lecture. Examinations were composed of recognition

Requests for reprints should be sent to Allen J. Schuh, School of Business and Economics, California State University, Hayward, California 94542. and recall items. During the last week of instruction, participants were shown the audio-video taped interview in their classroom setting. The exercise was like many others during the quarter that were designed to give students a realistic view of what practicing personnel people typically do. The last part of the course would be the reasonable time to show such an interview because it corresponds to the section in Cronbach's text on typical measures of performance.

The questions the interviewer asked on the tape were the same as on the student's interview guide. The students were encouraged to take notes. A form that the students were familiar with was provided, on which they were to evaluate the applicant for a management trainee position. The apparatus was positioned in the classroom. After general introductory remarks by the professor, the equipment was operated and the interview seen by the students. After viewing the 12-min interview, the students completed their evaluation forms and turned them in to the professor. The students were then handed a 25 -item test based on a transcript of the interview. Students had to take the test from memory, without the aid of notes taken during the interview. The students did not know that such a test would be given. No such surprise had occurred previously in the course. Although the students knew the professor would score the test, nothing was said about the impact of the test score on the student's final grade. The total time for the exercise was less than $30 \mathrm{~min}$.

\section{RESULTS}

The means and standard deviations for the three variables were calculated and compared between day and evening sections and were found to be not significantly different. Hence, the data for the two sections were combined and the intercorrelations of the three variables were calculated. The three intercorrelations were significantly $(p<.01)$ different from zero. The correlation between the interview scores and scores on the lecture material was .43. The correlation between the scores for the interview and scores on text material was .38. The correlation between scores on lecture and text material was .39. The highest and lowest correlations were compared and were found to be not significantly different. The Kuder-Richardson 
Formula 21 reliability estimates for the sets of scores were as follows: interview (.54), lecture material (.48), and text material (.78).

\section{DISCUSSION}

The results suggest that listening accuracy for class lecture material and employment interview material involves the same process as accuracy for material read in texts. Not only are the three sets of scores significantly related, their intercorrelations are not even significantly different. A single verbal information system accounts for the scores on the recognition-recall tests.

The ability to predict relative standing on an employment interviewing listening accuracy test from a paper-and-pencil test on material drawn from a textbook suggests that a personnel manager should construct such a test from assigned readings and, with forewarning to candidates for interviewing assignment, use the test for selection to interviewing duties. There should be more confidence placed in the report of interview impressions of probable work-related behaviors from an interviewer who has scored high on such a test than for someone who has scored low. Since job behavior inferences are based on reports of interview behaviors, such behaviors must be accurately recorded before the inferences can be valid. More attention needs to be given to the level of listening accuracy of interviewers and especially to possibilities for improving it.

\section{REFERENCES}

Aiken, E. G., Thomas, G. S., \& Shennum, W. A. Memory for a lecture: Effects of notes, lecture rate, and informational density. Journal of Educational Psychology, 1975, 67, 439-444.

Cronbach, L. J. Essentials of psychological testing. New York: Harper \& Row, 1970.

JENKINS, J. J. Remember that old theory of memory? Well, forget it! American Psychologist, 1974, 29, 785-795.

Mason, J. M. Questioning the notion of independent processing stages in reading. Journal of Educational Psychology, 1977, 69, 288-297.

SINGER, J. L. Navigating the stream of consciousness: Research in daydreaming and related inner experience. American Psychologist, 1975, 30, 727-738.

Wickelgren, W. A. The long and the short of memory. Psychological Bulletin, 1973, 80, 425-438.

(Received for publication January 14, 1978.) 